\title{
Lang dji Pota-lela: a Língua dos Pota
}

\author{
Lang dji Pota-lela: the language of Pota
}

Janina dos Santos Forte

Universidade Federal do Amapá(UNIFAP) ${ }^{1}$

Resumo. O presente trabalho trata de conhecimentos e práticas culturais indígenas do povo Karipuna que vive na Terra Indígena do Uaçá, no Estado do Amapá. O pota é uma prática cultural que envolve a cura e a causa de algumas doenças muitas vezes provocadas por seres sobrenaturais. O pota é reza, canto utilizado para proporcionar alívio ou até mesmo a cura dessas doenças, ele é realizado por pessoas especialistas, não necessariamente um pajé, podendo ser cantado, assobiado ou murmurado, muitas vezes, assoprado. Não se sabe ao certo a origem dessa prática, ela é muito utilizada por vários povos indígenas da região do Uaçá, por isso, o pota apresenta em sua constituição diferentes palavras de diferentes línguas da família Karib e Aruák além da língua Kheuol Karipuna. Neste trabalho, o meu objetivo é descrever as estruturas do pota identificando palavras das diferentes línguas utilizadas nas composições das rezas/canto utilizando meus conhecimentos empíricos e linguísticos. Além de descrever as estruturas do pota, registrei, através de áudio, 33 pota. Como pertencente ao povo Karipuna, sei da importância de resguardar esses saberes que fazem parte da nossa identidade.

Palavras-chave: Karipuna; Pota; Rezas; Línguas Indígenas; Língua Crioula; Documentação.

Abstract. This paper has as its object the potá pray, what is treated here as part of the knowledge and cultural practices of the Karipuna people who live in the Uaçá Indigenous Reservation, located in the State of Amapá, Brazil. The potá pray is a cultural practice that involves the processes of cause and healing of some diseases caused by supernatural beings. These processes are used to provide relief or even the cure of these diseases to the patients. They are performed by specialized people, who are not necessarily a shaman, and can evolve sing, whistle or even murmur. The Karipuna people does not know exactly the origin of the potá pray, although it is widely used by different indigenous peoples in the Uaçá Indigenous Reservation, what justify the fact that the pray its constituted by a variety of lexicon from different languages of the Karib and Aruak family besides the Kheuol Karipuna language. Considering these lexical characteristics of the potá pray, the goal of this paper is to describe its structures with special attention to the identification of words from different languages used along the process. To do this, using my empirical and linguistic knowledge as a member of that indigenous people, I will use a total of 33 potá pray recorded by me on the 2017 year.

Keywords: Karipuna ; Pota ; Prays ; Indigenous Language ; Creole Language ; Documentation.

\section{Introdução}

O povo Karipuna ainda mantem alguns rituais indígenas que são praticados desde os nossos ancestrais. Contam os nossos idosos, que o povo Karipuna possuía um vasto conhecimento de ervas associado ao xamanismo que proporcionavam alívio ou até mesmo a cura de algumas doenças. Um desses conhecimentos é o pota, rezas realizadas através de murmúrio, sopro e, que hoje, poucas pessoas ainda dominam na nossa comunidade. Tassinari (2007) define pota:

\footnotetext{
${ }^{1}$ Mestranda do Programa de Pós-Graduação em Letras (PPGLET); professora na Escola Indígena Estadual João Teodoro Forte, T. I. Uaçá (Oiapoque/AP), egressa da Licenciatura Intercultural Indígena da UNIFAP.
} 
Os potas são canções entoadas em voz muito baixa, próximo à cabeça ou ao corpo do doente, acompanhadas de sopros e pequenas cuspidelas. O som é baixo de forma a parecer mesmo um "sopro" e dizem que é ele que manda a doença embora.

Tobler (1987), em seu dicionário da língua Kheuol Karipuna, define pota como sendo uma palavra pertencente à classe verbal que significa "comunicar com os espíritos" e como substantivo "a oração dos índios".

Esse conhecimento era passado de geração a geração. Hoje, porém, está sendo substituído pelos conhecimentos dos não indígenas, pelas consultas médicas e os remédios comprados nas farmácias. O povo Karipuna está com grandes dificuldades em manter o pota, já que é um conhecimento de tradição oral, e que sofre muita discriminação por questões religiosas. O pota nunca foi escrito, existe somente algumas traduções para o português que foram feitas por alguns pesquisadores. Por existir somente na forma oral, hoje, o aprendizado do pota requer muitos treinos, pois é muito difícil entender as línguas faladas pelos assopradores e isso não desperta interesse nos jovens e assim, cada vez mais, poucas pessoas o praticam. Segundo Andrade (2007).

\footnotetext{
A agressão xamânica por meio dos potás eram antes bastante comuns, seja no Curipi, no Uaçá ou no Urukauá, e a acusação de fazê-la um dos principais fatores de dissensões entre famílias. A popularidade das fórmulas encantatórias era tão grande em Kumarumã que contou-me um interlocutor karipuna - as crianças a aprendiam apenas prestando atenção nos ensinamentos feitos aos adultos pelos grandes sopradores em rodas ao ar livre. De posse da fórmula na memória, os pequenos a recitavam sem controle como uma brincadeira, distribuindo doenças e infortúnios em sua comunidade.
}

A pesquisa apresentada neste Trabalho de Conclusão de Curso tem como objetivo descrever as estruturas do pota identificando as diferentes línguas utilizadas em suas composições. Para isso, eu me baseio em meus conhecimentos empíricos e linguísticos. Vou pesquisar a origem das palavras que compõe as letras do pota, quais as línguas faladas pelos assopradores quando executa o pota, quero saber se os mesmos conhecem essas línguas ou se apenas repetem sem ter entendimento do que estão falando. Pretendo descrever o processo de aprendizagem do pota, quais as técnicas usadas para se tornar um bom assoprador.

Outro objetivo é promover uma documentação do pota, através de gravações em áudio, transcrições e tradução. Com o acervo resultante do meu trababalho, pretendo promover o fortalecimento e o prestígio desse conhecimento e que possa garantir que as futuras gerações tenham acesso aos mesmos.

A pesquisa sobre o pota é muito relevante para o povo Karipuna, pois, na minha comunidade, aldeia Espírito Santo, o uso do pota ainda faz parte do cotidiano de algumas pessoas, ainda é utilizado regularmente no tratamento de alguns tipos de doenças, principalmente aquelas provocadas pelo sobrenatural. Precisamos manter esse conhecimento vivo dentro da comunidade, ele faz parte da nossa identidade Karipuna, precisamos fortalecer essa tradição para os nossos jovens conheçam e pratiquem.

Hoje, na nossa comunidade, estamos lutando para que os jovens tenham motivações para aprenderem com os mais velhos que detêm esses conhecimentos, pois o não repasse desse conhecimento implica no desaparecimento do pota, e é urgente que outras pessoas aprendam, pois os detentores desses conhecimentos estão morrendo. 


\section{O Povo Karipuna da região do Uaçá}

O povo Karipuna formou-se a partir de remanescentes de vários outros povos que se fundiram no rio Curipi (Tassinari, 2007). Segundo relatos das pessoas mais velhas, o povo Karipuna tem várias raízes, foi formado por índios e não-índios, por imigrantes fugitivos da cabanagem, movimento de revolta ocorrido no estado do Pará. Nesses relatos, as pessoas mais velhas dizem, também, que estes imigrantes eram todos homens e que, ao chegarem no Curipi se casaram com mulheres indígenas que viviam na região do Uaçá. Pelo fato de existirem poucos registros escritos dessa época, não se sabe ao certo que povos indígenas fizeram parte da formação deste povo.

O povo Karipuna atualmente tem uma população de aproximadamente 2.282 indivíduos (cf. FUNAI, 2017), espalhados em 18 aldeias, sendo elas: 12 aldeias às margens do rio Curipi: Manga, Japim, Benoa, Paxiubal, Pakapua, Txipidõ, Santa Isabel, Taminã, Espírito Santo, Kubahi, Kutiti, Açaizal; 4 aldeias ao longo da BR 156: Estrela, Ahumã, Piquia, Karia e 2 no rio Oiapoque: Kunanã e Uaha. Todas 18 aldeias encontram-se em duas terras indígenas, Terra Indígena Uaçá e Terra Indígena Juminã, demarcadas e homologadas desde 1993. Além dos Karipunas, vivem nessas Terras indígenas os povos Galibi Marworno, Galibi Kalinã e Palikur.

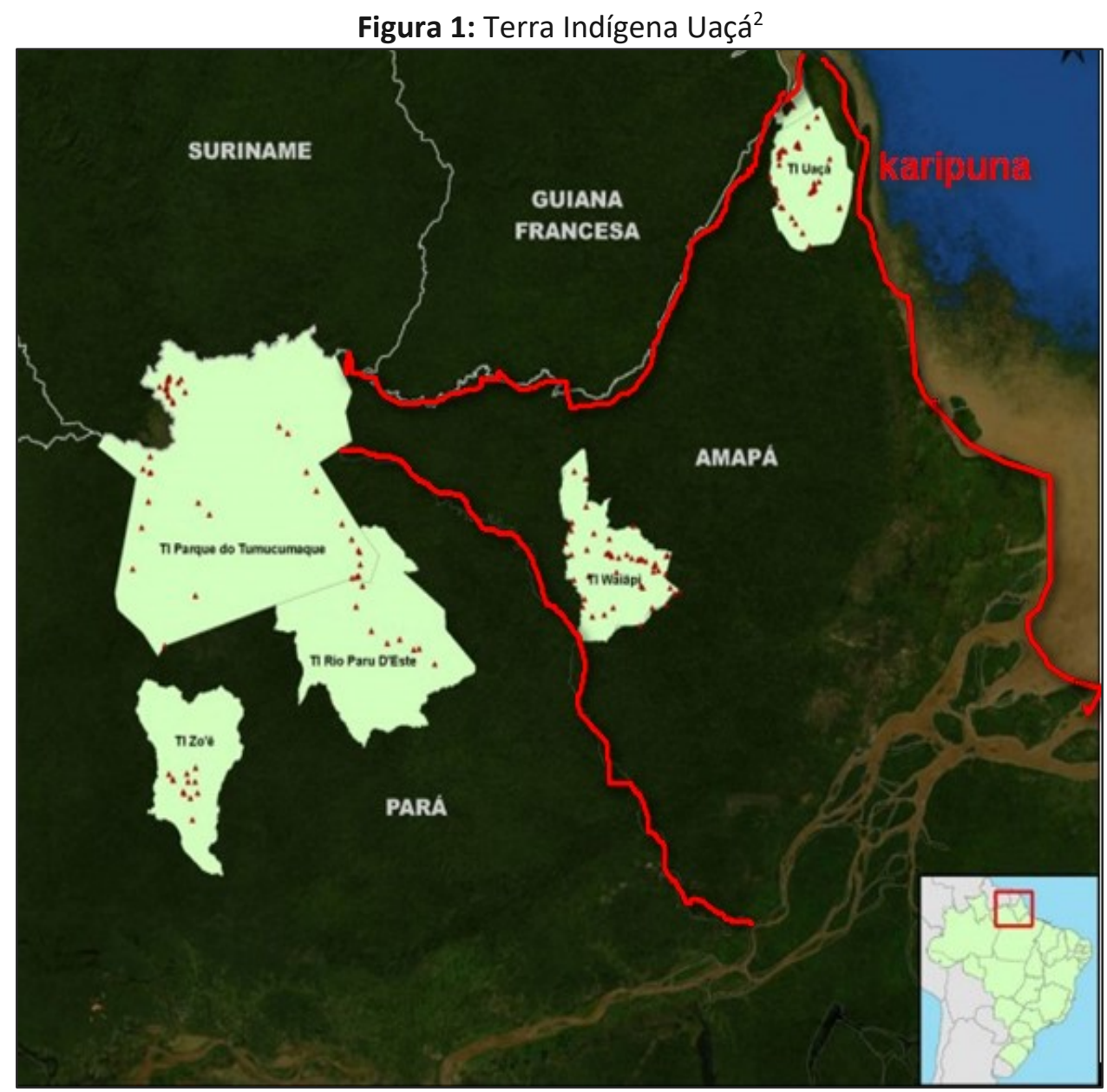

Fonte: lepé

\footnotetext{
${ }^{2}$ Figura modificada com a identificação do mapa do estado do Amapá e a indicação da localização do povo Karipuna (cf. http://www.institutoiepe.org.br/ acessado em 10/11/2017).
} 
Os Karipuna da aldeia Espírito Santo se consideram descendentes de dois grupos formados pelas famílias: Forte e Santos. Estes dois sobrenomes são muito comuns entre este povo que é falante da língua Kheuol Karipuna, língua de origem crioula que foi adquirida como língua materna depois da perda de sua língua original.

A aldeia Espírito Santo está localizada na Terra Indígena Uaçá, no município de Oiapoque-AP à margem direita do Rio Curipi em uma área montanhosa, cercada de campos que na época das chuvas ficam alagados.

\section{Uma pesquisa participante}

A minha pesquisa foi realizada na aldeia Espírito Santo, onde eu moro. Os dados da pesquisa foram coletados por mim, através de entrevistas feitas com três pessoas.

O seu Avelino Carivaldo dos Santos de 72 anos, aposentado, agricultor, trabalha com fabricação de cestas de palha, confecções de canoa e barcos entre outros artefatos. Ele foi cacique da aldeia durante treze anos na década de 1990 e foi uma das mais respeitadas lideranças da região do Uaçá. Quando mais jovem, tocava violino, rabeca, gaita, pandeiro nas festas católicas. Ele diz que aprendeu o pota em ocasiões dos mutirões ${ }^{3}$, festas, caçadas, pescarias onde tinha a oportunidade de ouvir os mais velhos cantando e fazendo rituais de cura usando o pota. Segundo o seu Avelino, ele sabe mais de cinquenta pota e diz que a maioria é na língua Palikur ${ }^{4}$ e que sabe o significado de algumas palavras. Entretanto, pelo fato de não praticar todos com frequência, ele tem esquecido de alguns pota.

A segunda pessoa entrevistada foi a dona Eliete Narciso, 89 anos. Ela é aposentada, viúva e agricultora e aprendeu os pota com o seu irmão e sua cunhada, uma mulher Palikur. Dos três pota que conhece, ela sabe o significado de algumas palavras e diz que alguns são na língua antiga dos Karipuna e outros em Palikur. Os pota que conhece são: hesipel solei que serve para curar erisipela ${ }^{5}$, doença originada pela exposição ao sol. Dona Eliete diz que: "quando uma pessoa tem alguma ferida e fica muito tempo no sol, a ferida começa a ficar vermelha, inchada e quente e, para curar, é preciso que se assopre o pota de erisipela".

O outro pota que ela sabe é o djisã, que significa sangue, é usado quando uma pessoa fica inchada sem nenhum motivo aparente, sente calafrios, nesses casos, dizem que essa pessoa passou no rastro de alguma mulher menstruada e por isso tem que ser assoprada com o pota de sangue. O último, o pota mivue, que significa espelho, é utilizado quando uma criança recém-nascida tem convulsões. Essas convulsões são provocadas pelo fato de seus pais terem visto seus reflexos no espelho, ou mesmo o próprio recém-nascido ter sua imagem refletida no espelho. Neste caso é usado o pota mivue para o tratamento. Dona Eliete disse que sabia outros pota mas, com a idade, ela se esqueceu da maioria.

O outro conhecedor de pota é o seu Clemildo Batista. Ele tem 57 anos, é agricultor, tem 10 filhos, estudou até a antiga 4a série, sabe ler e escrever. Ele conhece alguns pota, todos com função de cura, e quem o ensinou foram seus avós e algumas pessoas mais velhas. Seu Clemildo diz que

\footnotetext{
${ }^{3}$ Mutirões são trabalhos coletivos voluntários organizados pelo cacique ou na demanda particular que podem ser na limpeza da roça, construção de uma casa etc.

${ }^{4}$ A Palikur pertencente à família linguística Aruak. É falada pelo povo Palikur que vive na Terra Indígena do Uaçá.

${ }^{5}$ s. f. Med. Doença infecciosa aguda, febril, da pele e do tecido subcutâneo, causada por um estreptococo hemolítico (DIC Michael UOL - Dicionário digital).
} 
para aprender pota tem que ter a cabeça boa para decorar rápido, pois às vezes você ouve um pota apenas uma vez e se você não decorar, você com certeza vai esquecer. Outra forma de aprender é escrever o pota, da forma que o entendeu, foi assim que ele conseguiu aprender tantos pota.

As entrevistas foram desenvolvidas em três etapas. Na primeira, foram selecionadas as pessoas que fariam parte das entrevistas. Eu usei como critério para esta seleção, os mais idosos que tem conhecimentos dos pota e os praticam com frequência e que se disponibilizaram a participar como informantes. Na segunda etapa, foi a coleta de dados em campo. Eu comecei a realizar as gravações em julho de 2016 até maio de 2017. Neste período, eu gravei 30 minutos de áudio, entre entrevistas e pota. São 33 pota gravados, cada um em média de 30 segundo a sua execução. Gravei somente 03 entrevistas, as conversas sobre como o entrevistado aprendeu o pota, como ele faz para repassar este conhecimento. Nesse processo, percebi que os informantes não ficavam à vontade quando eu dizia que ia gravar, então resolvi somente anotar, assim consegui obter mais informações sobre o que eu estava pesquisando. Para o processo de gravação, tanto do pota quanto das entrevistas, eu utilizei um gravador HN5 ZOOM e um celular, modelo Sansung Galaxy J3.

Além das entrevistas e das conversas informais com pessoas que sabem pota e com pessoas que usam o pota para tratamento, eu também tive como subsídio as leituras do livro No Bom da Festa: O Processo de Construção Cultural das Famílias Karípuna do Amapá, TASSINARI (2003), que faz uma breve descrição do pota e cita alguns relatos desses conhecimentos antigos. Outra leitura que me deu elementos sobre o pota foi a tese do antropólogo Andrade (2007) - O Real que não é visto - xamanismo e relação no baixo Oiapoque/AP.

A terceira etapa, foi a organização dos dados, o processo de transcrição e tradução utilizando o programa ELAN ${ }^{6}$. Dos 33 pota gravados, transcrevi 15, e desses, 8 pota estão transcritos com quatro linhas de anotações: transcrição, tradução para Kheuol, tradução para o Português e notas. A transcrição foi de acordo com a pronúncia do falante, usando a ortografia do Kheuol Karipuna, pois nos pota encontrei palavras em Kheuol, em Kalinã e outras línguas desconhecidas. As palavras desconhecidas os informantes diziam que são na língua Karipuna antiga e sabem significados de algumas. Os outros 7 pota foram somente transcritos, pois os informantes não sabiam traduzir por completo, sabiam somente o significado de algumas palavras. Para a transcrição e tradução dos pota contei, também, com a participação dos entrevistados.

O planejamento deste trabalho foi fundamental para a sua realização. As entrevistas foram feitas de acordo com o tempo disponível e a quantidade de pota de cada entrevistado. A maioria foi realizada aos sábados e domingos pela parte da manhã, pois não era possível fazer as entrevistas nos dias da semana porque os entrevistados estavam trabalhando na roça neste período, então combinávamos o horário e eu ia até suas casas. No primeiro momento, eu conversei sobre o uso do pota na comunidade, como eles aprenderam o pota, quem ensinou eles, se usavam regularmente, em que momento e se achavam importantes esses conhecimentos. Também, perguntei se sabiam sobre o que os pota falam, em quais línguas os pota são executados. Depois desse primeiro contato começávamos as gravações, eles me explicavam para que serviam os pota antes de cada gravação. Cada pota era gravado separadamente.

\footnotetext{
${ }^{6}$ programa multimídia que permite o uso de áudio ou vídeo, usado para transcrever e traduzir eventos de fala https://tla.mpi.nl/tools/tla-tools/elan/ [acessado em 08 de maio de 2017].
} 
A foto abaixo é o registro do momento da gravação de pota na casa do seu Avelino.

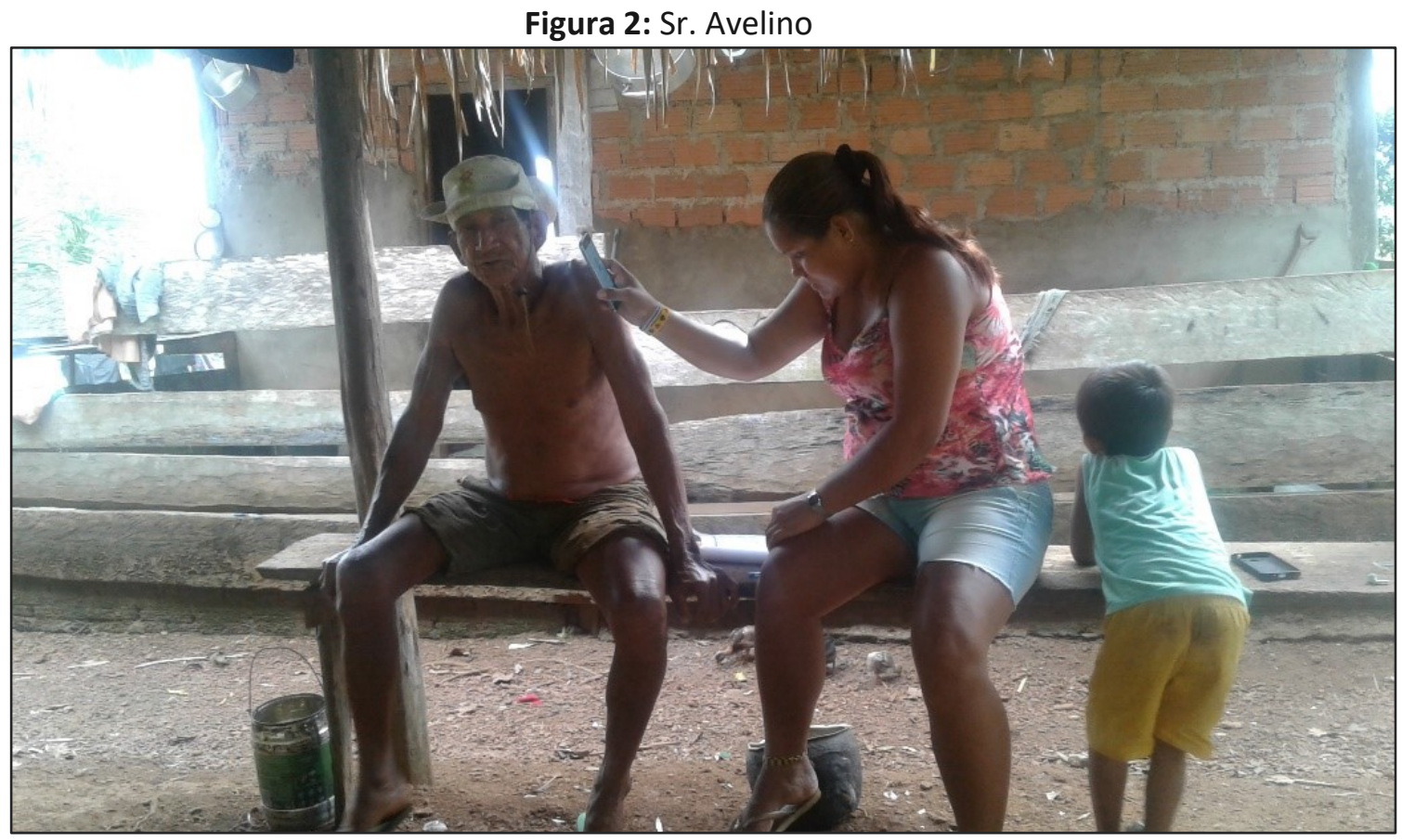

Foto: Rodinaldo dos Santos

\section{Os pota, tipos e usos}

O pota é uma prática cultural que envolvem a cura e a causa de algumas doenças. Esta prática não necessariamente está ligada diretamente aos pajés. Os conhecedores de pota podem ser pajés ou pessoas comuns, homens ou mulheres que aprenderam com os pais ou pessoas mais velhas. $\mathrm{Na}$ aldeia, os conhecedores de pota são chamados de "assopradores".

O pota pode ser usado para fazer o bem e para fazer o mal. O efeito depende da intenção do contratante do serviço. São vários os pota que são usados para fazerem o bem, existem aqueles que são usados para tratar doenças causadas pelos seres sobrenaturais que por algum motivo interferiram na vida das pessoas; existem, também, aqueles que são para evitar espíritos de pessoas mortas; e há alguns específicos para doenças de crianças. Os pota, também, são usados para proteger as pessoas, principalmente as crianças que são mais vulneráveis. E os pota que são usados para o amor, para conquistar a pessoa amada ou fazer com que uma pessoa passe a amá-lo.

\subsection{Os pota do bem}

Abaixo, apresento alguns pota, utilizados para fazer o bem, com alguns comentários a respeito. As informações dos pota é uma compilação das informações dadas pelos informantes.

(1) pota djivã gho kẽkẽ nuit - pota na frente de piaçoca grande da noite

kẽkẽ nuit é uma ave que anda à noite e é muito traiçoeira, quando alguém a encontra ou passa por cima do seu rastro, a pessoa fica torta ou paralítica, é como se sofresse um derrame. O pota djivã gho kẽkẽ nuit é usado para o tratamento deste mal. 
(2) aple nam tximun - chamar a alma de crianças

Acredita-se que quando as crianças ficam assustadas, sempre chorando, é porque suas almas saem de seus corpos e elas ficam doentes. O pota aple nam tximun é usado para chamar a alma da criança de volta para o seu corpo.

(3) hãje tximun ie van djivã piã - curar a barriga de criança na frente de mucura ${ }^{7}$ Quando as crianças são pequenas, elas não podem comer qualquer alimento porque provoca diarreia e vômito. Este mal é tratado com o pota hãje tximun ie van djivã piã, que chamamos em português de pota da mucura, por ela ser um animal com um intestino muito resistente.

(4) pota taparaxixi - pota martim-pescador taparaxixi é a ave conhecida como martim-pescador. Quando os meninos são pequenos, eles são assoprados com este pota para que sejam um bom pescador. Dizem que é recomendável assopra-los depois que eles já souberem nadar, pois as crianças vão querer sair pra pescar sozinhas e podem cair na água.

5 - pota djivã nam - pota na frente da alma

Os Karipuna acreditam que quando uma pessoa morre, não podemos chamar seu nome se não sua alma ataca nosso corpo. Quando uma pessoa está doente seu corpo está vulnerável e é nessa hora que algumas almas malignas se aproveitam e atacam o corpo. Os sintomas são: pernas e pés muito frios. Os assopradores dizem que é preciso descobrir de quem é alma que está atacando a pessoa, isso é possível saber quando o doente geralmente apresenta os mesmos sintomas da doença que a outra pessoa morreu.

\subsection{Os pota do $\mathrm{mal}$}

O pota pode ser também usado para fazer o mal, existem aqueles que as pessoas usam para se vingar causando muito mal a uma pessoa atingida. Há dois tipos de doenças muito comuns causadas pelos pota, que são: "suflê" e "piai". Os suflẽ são feridas ou bolinhas que aparecem geralmente na pele, coçam muito e se espalham rapidamente pelo corpo, dependendo do tipo de pota usado pode ser algo simples ou muito grave. O piai, dizem os mais velhos, é muito pior do que o suflẽ, pois na maioria das vezes não tem tratamento, a pessoa morre muito rápido.

\section{Análise dos pota}

Em Tassinari (2003), sobre o tratamento dos "sopradores", ela diz que "Essas terapias são chamadas "sopros" ou, em patois: sufle e pota". Em sua análise, ela atribui línguas diversas a essas canções.

Jean Mocquet (1617), apud Tassinari (2003), define o nome pota como sendo de origem Karib com o significado de boca. De acordo com os meus entrevistados, os pota já apresentavam uma estrutura formada a partir de várias palavras de diferentes línguas da família Karib e Aruak. Hoje, além dessas línguas, os assopradores Karipuna afirmam que os pota são formados por palavras da língua antiga Karipuna e a atual língua Kheuol Karipuna.

\footnotetext{
${ }^{7}$ a tradução literal do pota hãje tximun ie van djivã piã é curar barriga da criança na frente de mucura - acredita-se que, pelo fato da mucura se alimentar de tudo, ela não passa mal, tem um intestino forte.
} 
Em busca desta confirmação, eu fiz uma rápida pesquisa ${ }^{8}$ com falantes de línguas da família Karib e Aruak e obtive as seguintes informações:

Na língua Apalai ${ }^{9}$, a palavra potapihpo significa "lábio"; os verbos apontar, mostrar algo é "ene pota". Em Galibi Kalinã ${ }^{10}$, pota tem o mesmo significado de "boca". Em Kuikuro11, uma língua da família Karib, a palavra para bico, ponta é [ho'ta] ${ }^{12}$ hota. Em Tiriyo ${ }^{13}$, boca é [mi'ta] mïta, ponta [i'poti] ipotï, assoprar [ipu'ka] ipuka. Já em Palikur ${ }^{14}$, uma língua da família Aruwak, a palavra para boca é pibi, para assoprar, pũ.

Diante dos dados, não nos restam dúvidas que a palavra pota é de origem Karib, que é usada para nomear um conhecimento que, hoje, faz parte da cultura imaterial dos povos indígenas Karipuna, Galibi-Marworno e Palikur que habitam a terra indígena do Uaçá.

Segundo os assopradores, a maioria dos pota são executados na língua antiga "lãdã lang", a língua dos nossos antepassados, misturada com palavras em língua Palikur e, com algumas palavras de línguas da família linguística Karib, como a língua Kalinã. Um exemplo da presença de palavras Kalinã é a palavra para água, que em Kalinã é "tunã", ela aparece em pota que cura alguma enfermidade relacionada à água. Como exemplo do uso da palavra tunã, apresento abaixo um trecho da sessão do pota gho kẽkẽ nuit, transcrita e traduzida para o Kheuol Karipuna e Português.

(i) file:///D:/POTA/trs lut aple nam tximun.eaf

Quinta-feira, 30 de Agosto de 2017 13:26

ACtrs kuruemĩ kuruemĩ ximoroganĩ

ACtrkh vã vã ale u ximẽ

ACtrpt vento, vento, vai embora

ACnt neste momento o assoprador está mandando o vento embora.

(ii) file:///D:/POTA/trs Pasu mutõ.eaf

Quinta-feira, 15 de junho de 2017 18:54

ACtrs uaikõre uaikõre... ximoroganĩ...uaikõre...

ACtrkh pasu mutõ pasu mutõ... ale u ximẽ pasu mutõ....

ACtrpt preguiça, preguiça, vai embora preguiça...

ACnt o assoprador está mandando o espírito da preguiça embora(neste momento ele assopra).

(iii) file:///D:/POTA/ trs gho keke nuit 2.eaf

Quinta-feira, 20 de abril de 2017 13:58

\footnotetext{
${ }^{8}$ A pesquisa foi feita no Campus Binacional na etapa de janeiro de 2017, com os alunos do curso de Licenciatura Intercultural Indígena.

${ }^{9}$ Ariné Apalai - informante do dado - aluno do Curso de Licenciatura Intercultural Indígena

${ }^{10}$ Cristina Lod - Etnia Kalinã - informante do dado

11 Takumã Kuikuro - Etnia Kuikuro - informante do dado

${ }^{12}$ Em Kuikuro existe uma restrição rígida de ocorrência da consoante /p/ em posição inicial de palavra, onde se encontra sistematicamente [h]: $\mathrm{p} \rightarrow \mathrm{h}$ / \#____ (informação verbal Comunicacao Pessoal, Mara Santos - abril/2017)

${ }^{13}$ Mitori Tiryo - Etnia Tiryo - informante do dado - aluno do Curso de Licenciatura Intercultural Indígena

${ }^{14}$ Gleidson Palikur - Etnia Palikur - informante do dado
} 
ACtrs ximoroganĩ... kãuẽuẽroã̃...

ACtrakh ale u ximẽ kẽkẽ nue

ACtrapt vai embora piaçoca preta

ACnt o assoprador está mandando a piaçoca ir embora e deixar o corpo do doente.

Como já disse, os pota são formados de palavras de diferentes línguas pertencentes à diferentes famílias linguísticas, algumas palavras conhecidas e outras palavras desconhecidas. As palavras desconhecidas são consideradas como pertencentes à língua antiga Karipuna. Em diferentes pota que eu transcrevi com a ajuda do seu Avelino, nós identificamos vários nomes de animais na língua antiga que ele traduzia para o Kheuol Karipuna, como podemos observar nos 3 trechos abaixo:

(i) file:///D:/POTA/trs Maipuhi.eaf

Quarta-feira, 17 de maio de 2017 17:00

ACtrs uaudẽbie uaudẽbie uaudẽbie... (sabe a tradução, mas desconhece a origem da palavra)

ACtrkh maipuhi maipuhi maipuhi...

ACtrpt anta, anta, anta... anta, anta, anta...

ACnt este pota é pra da força, pois a anta 'é um animal muito forte e grande.

(ii) file:///D:/POTA/trs Pasu mutõ.eaf

Quinta-feira, 15 de junho de 2017 18:54

ACtrs uaikõre... uaikõre... uaikõre... uaikõre...

(sabe a tradução, mas desconhece a origem da palavra)

ACtrkh pasu mutõ.... pasu mutõ... pasu mutõ...

ACtrpt preguiça... preguiça... preguiça...

ACnt Referente a um animal conhecido como preguiça.

(iii) file:///D:/POTA/ trs gho keke nuit 2.eaf

Quinta-feira, 30 de março de 2017 13:58

ACtrs kãuẽuẽroã... kãuẽuẽroã... kãuẽuẽroã...

(sabe a tradução, mas desconhece a origem da palavra)

ACtrakh kẽkẽ nue... kẽkẽ nue... kẽkẽ nue....

ACtrapt piaçoca preta... piaçoca preta... piaçoca preta...

Como podemos observar, as informações semânticas dessas palavras ainda estão presentes, muitos assopradores ainda conseguem identificar nomes de animais, mas não conseguem identificar a origem das palavras, muitas vezes eles dizem que estas palavras pertencem à língua antiga Karipuna. De fato, é necessário fazer uma pesquisa nas outras línguas da família Karib e Aruak para confirmar se essas palavras fazem parte dos seus léxicos ou não. Nos pota, mesmo sabendo que existe uma palavra em Kheuol para traduzir os nomes dos animais, se utiliza a palavra original.

Além do conhecimento de algumas palavras que não tem sua origem identificada, alguns assopradores, que tem um profundo conhecimento dos pota, conseguem identificar morfemas gramaticais que compõem as palavras. Como exemplo, vamos analisar o pota taparaxixi. Seu Avelino, 
o executor desse pota, que me ajudou a transcrever, ainda conhece algumas palavras da língua antiga. No caso de taparaxixi-ĩbo, ele identificou o sufixo -ĩbo como algo ruim, algo que não presta.

file:///D:/POTA/trs taparaxixi.eaf

Quinta-feira, 20 de agosto de 2017 17:16

ACtrs taparaxixi, taparaxixi, taparaxix-ĩbo...

ACtrkh matẽ pexo, matẽ pexo, matẽ pexo pa bõ...

ACtrpt martim-pescador, martim-pescador, martim-pescador é ruim...

ACnt este pota se refere a uma ave, o martim-pescador.

O morfema -ĩbo é um sufixo que tem o sentido de algo ruim, só é encontrado nos pota, os assopradores dizem que ele faz parte da antiga língua dos Karipuna. É um sufixo muito produtivo, e já reconhecido pelos assopradores que o usam em palavras da língua Kheuol de hoje como podemos observar no trecho do pota kauixi a seguir.

file://D:/TCC-JANINA/POTA/kauixi.eaf

Quarta-feira, 12 de maio de 2017 19:07

ACtrs kauix-ĩbo...

ACtrkh kauixi ki pa bõ

ACtrpt urtiga não presta

Aqui, a construção é muito interessante, o morfema -ĩbo é sufixado à palavra kauixi, que é uma palavra da língua Kheuol Karipuna.

file:///D:/TCC-JANINA/trs iapo.eaf

Sexta-feira, 08 de maio de 2017 15:31

ACtrs tauakõko.... tauakõko...tauakõko-ĩbo....

ACtrkh iapo... iapo... iapo pa bõ...

ACtrpt japim... japim... japim não presta

No pota iapo, o morfema -ĩbo está sufixado a palavra tauakõko que não foi identificada sua origem, em Kheuol Karipuna é iapo, que é o nome de um pássaro, que em português é o japim.

Acredita-se que o conhecimento do pota tem várias raízes. Os mais velhos contam que seus pais aprenderam com viajantes que passavam pela região do Uaçá. Outros dizem que antigamente eles saiam de suas aldeias para aprenderem com curandeiros de outras comunidades, pois estes sofriam com doenças que só poderiam ser curadas com pota. Portanto, a mistura de palavras de línguas diferentes é resultado do intenso contato entre os povos que habitam as terras indígenas do Uaçá e Juminã. A origem do pota foi diluída pelo uso e apropriação de todos. Hoje, tanto os Karipuna, Galibi Marworno, Palikur e Galibi Kalinã ainda praticam o uso do pota para curar as doenças específicas dos seus povos. 


\section{Organização e estrutura do pota}

Os pota são compostos, em sua maioria, por no mínimo duas orações, sendo que estas orações possuem de duas a cinco palavras. Dessas palavras, algumas formam o refrão e se repetem de seis a sete vezes dentro do pota.

O que vai definir o tanto de vezes que o pota será repetido é o estado de saúde da pessoa tratada, pois dependendo da situação de saúde serão necessários mais ou menos assopros, ou seja, a repetição do pota.

A maioria dos pota se refere a lugares habitados por seres sobrenaturais, nomes de animais, plantas, fenômenos naturais, como vento, chuva. Os pota podem ser falados e assobiados. Os falados podem ser rezados e cantados. A maioria das pessoas que pratica o pota prefere realizá-los assobiando e cantando, na maioria das vezes num tom de voz bem baixo quase imperceptível, um sussurro, uma estratégia utilizada para proteger os seus pota daqueles que querem aprender sem pedir permissão.

Abaixo, apresento a transcrição de cinco $^{15}$ pota para entendermos como são estruturados e como as palavras utilizadas são combinadas em sua composição, suas origens e significados. Todos os cinco são cantados e traduzidos pelo seu Avelino.

(1) pota djivã gho kẽkẽ nuit kãuẽuẽroã... kãuẽuẽroã... kãuẽuẽroã... (1 palavra, 3 repetições) ] refrão kãuẽuẽroã...kãuẽuẽroã...kãuẽuẽroã... (1 palavra, 3 repetições) matupa matupa tunã tunã kãuẽuẽroã...kãuẽuẽroã... (2 palavras, 2 repetições) kãuẽuẽroã...kãuẽuẽroã...kãuẽuẽroã... (1 palavra, 2 repetições) matupa matupa tunã tunã (1 palavra, 3 repetições) kãuẽuẽroã...kãuẽuẽroã... mẽkoro.. ( 2 palavras, 2 repetições) ( 2 palavras, 2 e 1 repetição) ximorogãnĩ... kãuẽuẽroã... (2 palavras)

Identificação de algumas palavras:

kãuẽuẽro: piaçoca preta (ave que vive na beira do rio) matupa: barranco - Kheuol Karipuna

tunã: água - Galibi Kalinã mẽkoro: negro

ximoroganĩ vai embora

As palavras kãuẽuẽro, mẽkoro e ximoroganĩ, segundo seu Avelino, elas são da língua antiga Karipuna.

(2) aple nam tximun - chamar a alma de crianças korouemĩ korouemĩ korouemĩ korouemĩ korouemĩ korouemĩ tamã ueuei tamamã a mimĩ

(1 palavra, 3 repetições ) ] refrão (1 palavra, 3 repetições ) $\}$ (4 palavras sem repetição ) $\}$

\footnotetext{
${ }^{15}$ Estes pota foram gravados para análise de sua estrutura, não tem repetição do todo, foram cantados uma vez
} somente. 
korouemĩ korouemĩ

tamã ueuei a tamamã a mimĩ

korouemĩ korouemĩ ximoroganĩ
(1 palavra, 2 repetições )

(4 palavras sem repetição )

( 2 palavras, 2 repetições )

Identificação de algumas palavras:

korouemĩ vento

tamã: voltar

tamamã: volta pra sua mãe

mimĩ: criança

ximoroganĩ: vai embora

Todas as palavras acima foram identificadas como sendo da língua antiga Karipuna.

(3) hãje tximun ie van djivã piã - curar a barriga de criança

tõre... tõre... tõre...

tõre... tõre... tõre..

uparekãbo totxikamẽbo

tõre... tõre...

uparekãbo totxikamẽbo

tõre... tõre... ximoroganĩ

tõre... tõre...
(1 palavra, 3 repetições) ] refrão

(1 palavra, 3 repetições)

( 2 palavras, sem repetição)

(1 palavra, 2 repetições)

( 2 palavras, sem repetição)

(2 palavras, 2 repetições)

(1 palavras, 2 repetições)

Identificação de algumas palavras:

tõre: mucura

uparekãbo: filhos da mucura

totxi: jabuti - Kheuol Karipuna

mẽbo: pequeno - Galibi Kalinã

No pota acima, observamos a presença de palavras em Kheuol Karipuna, Kalinã e língua antiga Karipuna. Isso mostra que o pota é um exemplo claro do intenso contato linguístico entre os povos da região.

Na construção uparekãbo totxikamẽbo, de acordo com as informações obtidas na minha pesquisa, podemos assim analisá-la:
u-pa-re-kãbo
totxi-ka-mẽbo
$2 \mathrm{p}$-não-querer-moqueado
jabuti-?-pequeno

u pa le bukanẽ txi totxi?

"você não quer jabuti pequeno moqueado?"

Eu considero u-pa - Kheuol Karipuna; kãbo - Galibi Kalinã; totxi - Kheuol Karipuna; -ka?; mẽbo - Galibi Kalinã.

Outros pota:

(4) pota taparaxixi

taparaxixi... taparaxixi... taparaxixi...

taparaxixi... taparaxixi... taparaxixĩbo...

oumarikãbo i tutairanã

(1 palavra, 3 repetições) ] refrão

taparaxixi...taparaxixi...taparaxixi...

(2 palavra, 3 repetições)

(2 palavras, sem repetição) $\}$

taparaxixi... taparaxixi... taparaxixĩbo...

(1 palavra, 3 repetições)

oumarikãbo i tutairanã

( 2 palavra, 3 repetições)

taparaxixi... taparaxixi... taparaxixi...

( 2 palavras, sem repetição)

(1 palavra, 3 repetições)

taparaxixi... taparaxixi... taparaxixĩbo ximoroganĩ... (3 palavras, 2 repetições) 
Identificação de algumas palavras:

taparaxixi: martim-pescador

oumarikãbo: oumari-kãbo - lugar-queimado - lugar para plantar banana

tutairanã $\tilde{a}^{16}$ : no fundo do mato

-îbo: algo ruim, que não presta

(5) pota djivã nam

iatõbo... iatõbo... iatõbo...

iatõbo... iatõbo... iatõbo...

iapakanu iapakanu

(1 palavra, 3 repetições) ] refrão

iatõbo... iatõbo

(1 palavra, 3 repetições)

( 2 palavras, 1 repetição)

(1 palavra, 1 repetições)

iapakanũ iapakanũ tõbo tõbo

(2 palavras, 2 repetições)

ximoroganĩ iatõbo

( 2 palavras, 1 repetição)

Identificação de algumas palavras:

iatõbo: lugar onde a pessoa foi enterrada

iapakanũ: caixão

tõbo: no fundo

ximoroganĩ: vai embora

Todas as palavras acima são identificadas como palavras da língua antiga Karipuna.

Como podemos observar, a estrutura dos pota segue uma regra constante, além da melodia, existe um número de palavras que se combinam na repetição. O que chamamos de refrão é o conjunto de palavras que tem o maior número de repetição e que marca o início da repetição de todo o pota. A palavra repetida é sempre o nome do ser que é chamado para executar o pedido, seja para fazer o bem ou para fazer o mal. A repetição é uma estratégia para a memorização, para ajudar no aprendizado. O final é sempre fechado com a palavra ximoroganĩ que quer dizer "vai embora", quando o assoprador manda embora aquilo que está fazendo mal ao seu paciente.

\section{0 processo de aprender e ensinar o pota}

Em entrevista com seu Clemildo ${ }^{17}$, eu tentei entender o processo de ensinamento e de aprendizado dos pota, como ele consegue aprender e gravar tantas informações na mente. Para responder às questões, ele me contou como foi a experiência dele quando se interessou em aprender pota.

JS você sabe algum pota? ${ }^{18}$

$\mathrm{CL}$ eu sei, não muito, mas eu sei

JS como você aprendeu estes pota?

$\mathrm{CL}$ estes pota eu aprendi com os mais velhos de antigamente, com o senhor Manué Linéi primeiro, depois com o meu finado avô

$\mathrm{CL}$ eu aprendi no Taminã ${ }^{19}$, era aí que nós estávamos

JS onde você aprendia, quando estava em casa ou quando estava na roça?

$\mathrm{CL}$ eu aprendi em casa, outros em mutirão, assim a gente ...cantava... enquanto o

\footnotetext{
${ }^{16}$ Este termo foi identificado com o mesmo significado pelo pajé Colombo citado em Tassinai (2003).

17 file:E:\POTA \trans entrevista clemildo.eaf , Segunda-feira, 24 de Julho de 2017 17:39 - JS - entrevistadora - Janina Santos; $\mathrm{CL}$ - entrevistado - Clemildo Batista

18 texto é a transcrição ipsi literis da entrevista.

19 Taminã é uma aldeia Karipuna que fica no rio Curipi na Terra Indígena Uaçá
} 
amigo bebia e cantava, depois eu perguntava pra ele, indagava...sobre o que era e pra que servia (pota) e ele me dizia, assim eu aprendi...

JS como você fez pra que ficassem na sua cabeça? como....

$\mathrm{CL}$ pra fica na minha cabeça?

JS sim, se você escreveu ou....

$\mathrm{CL}$ não! eu gravei na cabeça mesmo

JS só uma vez ou duas, três vezes?

$\mathrm{CL}$ não, só uma vez, só uma vez

JS depois você perguntava como é que se usava?

$\mathrm{CL}$ sim, depois, depois eu perguntava pra que servia e eles me falavam

JS quanto tempo você demorou pra aprender ou aprendeu logo?

$\mathrm{CL}$ sim, logo que eles cantavam, é cantar que eles cantavam. Eu aprendi de cantar... é assim.

Perguntei ao seu Clemildo como é o processo de ensinamento dos pota.

JS você já ensinou outras pessoas? outras pessoas já aprenderam com o você?

$\mathrm{CL}$ eu já ensinei várias pessoas, só não sei se eles aprenderam

JS como você faz pra ensina, você canta pra eles?

$\mathrm{CL}$ sim, eu canto

JS você canta pra eles ouvirem né?

$\mathrm{CL}$ Sim

IS cada pota tem sua maneira de ser usada?

$\mathrm{CL}$ sim...pois se for $\sin ^{20}$

JS quantas vezes você canta cada pota? tem uma sequência ou é de acordo com o estado da pessoa, isso é, conforme a quantidade de palavras que tem no pota? Vamos supor no tratamento de alma, quantas vezes você assopra? ou pode assoprar quantas vezes quiser?

$\mathrm{CL}$ sim, quantas vezes quiser, mas no máximo sete vezes

JS sete vezes?

$\mathrm{CL}$ até a pessoa voltar ao normal, sim, ela volta ao normal

JS então não tem um número certo?

$\mathrm{CL}$ não tem número certo pra isso.

O pota é praticado por pessoas que detém o seu conhecimento, cada pota tem seu dono, para aprender um pota a pessoa tem que pedir ao dono para o ensiná-lo. Os donos de pota geralmente são pessoas mais velhas, mas isso não quer dizer que pessoas mais novas não podem praticar o pota. Para praticar o pota, a pessoa tem que aprender e saber utilizar o mesmo. A grande dificuldade encontrada pelos poucos jovens interessados em aprender o pota é o não conhecimento das línguas faladas nestes, o que dizem ser muito complicado já que não sabem o que estão dizendo. Os assopradores ressaltam que aprender e praticar o pota requer dedicação e tempo, dizem que antigamente era mais fácil repassar estes conhecimentos aos mais novos, pois naquela época os jovens tinham mais contato em diferentes momentos do cotidiano da aldeia, como em mutirão, na

${ }^{20}$ É o efeito negativo sofrido pela criança de algo feito pelos seus pais (por exemplo: se um pai atira em um animal, mas o animal não morre na hora, morre depois no meio do mato, o filho do atirador ficará doente, sendo tratado através do uso de pota) 
roça, em casa antes de dormir, nas festas de santo, no turé, em todos esses momentos os pota eram praticados e os jovens aprendiam naturalmente. Hoje os jovens estão muito dispersos e preocupados com outras coisas, não tem mais tempo e paciência para o processo de aprendizagem do pota.

O processo de aprender e ensinar pota depende muito da pessoa que estiver interessada em aprender, se a pessoa acredita mesmo, tem um certo dom. Seu Clemildo aprendeu somente ouvindo, ele tem a capacidade de decorar muitos pota em pouco tempo.

Segundo seu Avelino, em conversa informal, ele me disse que há também algumas restrições no que se refere ao ensinamento de alguns pota como, por exemplo, não se pode ensinar alguém mais velho, pois acredita-se que a pessoa mais velha já não consegue passar a força do pota, este perde a sua força, é aconselhável que uma pessoa mais velha ensine o mais novo. Qualquer pessoa que tiver vontade de aprender o pota pode ser ensinado, os mais velhos dizem que a melhor fase para aprender é quando se é criança, independentemente de ser homem ou mulher. O não indígena também pode aprender pota, se ele acredita neste tipo de tratamento. Antigamente os assopradores preferiam ensinar apenas para seus familiares para que este conhecimento não saísse do meio da família.

\section{Considerações finais}

Descrever o pota identificando sua estrutura, as diferentes línguas utilizadas em suas composições foi o principal objetivo deste trabalho. Para isso, eu transcrevi 15 pota juntamente com os assopradores para que eles me auxiliassem na identificação da origem e significados das palavras que compõem os mesmos. Eu observei que os pota são formados de palavras de diferentes línguas, algumas destas palavras são conhecidas e outras são desconhecidas. As palavras desconhecidas são consideradas, segundo os assopradores, como pertencentes à língua antiga Karipuna. Como os pota são relacionados a animais, vegetais e fenômenos da natureza, muitas palavras que compõem o pota são nomes de animais e são facilmente traduzidas para o Kheuol Karipuna. Outro dado interessante, descoberto nesta pesquisa, é o reconhecimento do morfema gramatical -ĩbo que tem um significado de algo ruim, que acompanha palavras de origem não identificada e palavras do Kheuol Karipuna, mas somente no pota. Quanto à estrutura do pota, segue uma regra constante, além da melodia, existe um número de palavras que se combinam na repetição. O que chamamos de refrão é o conjunto de palavras que tem o maior número de repetição e que marca o início da repetição de todo o pota. A palavra repetida é sempre o nome do ser que é chamado para executar o pedido, seja para fazer o bem ou para fazer o mal. A repetição é uma estratégia de memorização,

ajuda no aprendizado. O final é quase sempre fechado com a palavra ximoroganĩ que quer dizer "vai embora", quando o assoprador manda embora aquilo que está fazendo mal ao seu paciente.

Outro objetivo foi documentar os pota. Durante a minha pesquisa, eu gravei 30 minutos de áudio, entre entrevistas e pota. Destes são 33 pota gravados, cada um em média de 30 segundo a sua execução; 03 entrevistas com os especialistas em pota; dos 33 pota gravados, transcrevi 15, e desses, 8 pota estão transcritos com quatro linhas de anotações: transcrição, tradução para Kheuol, tradução para o Português e notas; os outros 7 pota foram somente transcritos. Para a transcrição e tradução dos pota contei, também, com a participação dos entrevistados. 
A comunidade ainda hoje utiliza com frequência o pota como tratamento. Esses conhecimentos têm uma grande importância no que se refere à saúde do corpo e da alma dos indígenas que ali vivem. Os pota assim como servem para fazer o bem também podem fazer o mal, por isso há um cuidado muito grande dos mais velhos na hora de repassá-los aos mais jovens, tem de ser pessoas responsáveis que não usem esses saberes para fazerem o mal.

\section{Relação dos entrevistados}

Nome: Avelino Carivaldo dos Santos

Idade: 72 anos

Etnia: karipuna

Mora na aldeia: Espírito Santo

Nome: Clemildo Batista

Idade: 57 anos

Etnia: karipuna

Mora na aldeia: Espírito Santo
Nome: Eliete Narciso

Idade: 89 anos

Etnia: karipuna

Mora na aldeia: Espírito Santo

\section{Referências}

ANDRADE, U. M. O Real que não é visto: xamanismo e relação no baixo Oiapoque-AP. 2007. Tese (Doutorado), Faculdade de Filosofia, Letras e Ciências Humanas, Universidade de São Paulo, São Paulo. 2007

MICHAELIS: Dicionário Brasileiro da Língua Portuguesa. São Paulo: Melhoramentos. Disponível em: <https://michaelis.uol.com.br/moderno-portugues>. Acesso em nov. 20189

TASSINARI, A. M. I. No Bom da Festa: o processo de construção cultural das famílias Karipuna do Amapá. São Paulo: EdUSP, 2003.

TOBLER, A. W. Dicionário CRIOULO KARIPÚNA/Português, PORTUGUÊS/Crioulo Karipúna. Brasília: SIL, 1987. Disponível em: <https://www.silbrasil.org.br/resources/archives/17099>. Acesso em nov. 2019. 